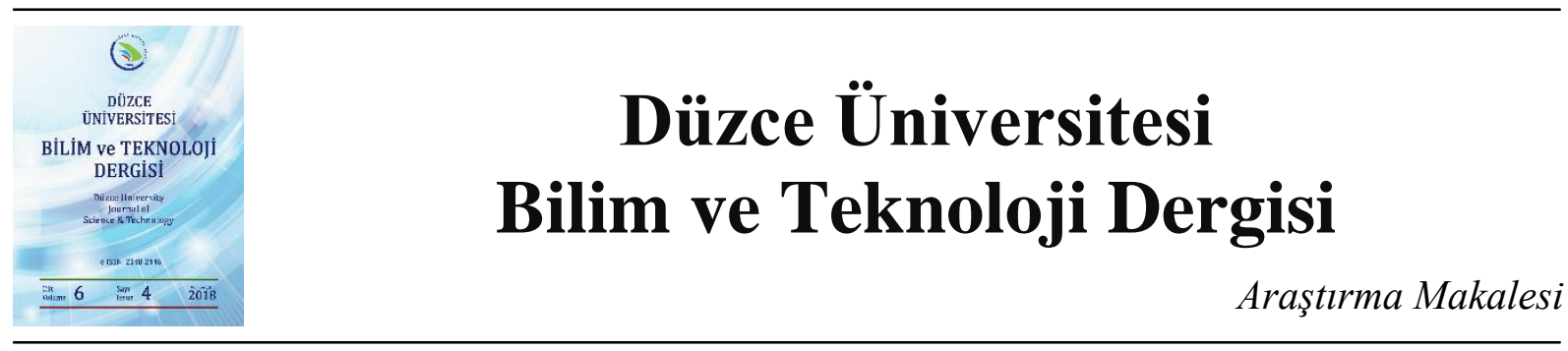

\section{Doğal Kenevir Lifi Kullanımının Asfalt Beton Karışımlara Etkisi}

\author{
Sercan SERIN ${ }^{a^{*}}$, Mustafa Erdal MACIT ${ }^{\text {a }}$, Eren Can ÇINAR ${ }^{\text {a }}$, Serkan ÇELIK ${ }^{\text {a }}$ \\ a Inşaat Mühendisliği Bölümü, Teknoloji Fakültesi, Düzce Üniversitesi, Düzce, TÜRKIYE \\ * Sorumlu yazarin e-posta adresi : sercanserin@duzce.edu.tr
}

\begin{abstract}
ÖZET
Günümüzde çeşitli bitkilerin lifli kısımları doğaya atık malzeme olarak terkedilmektedir. Diğer taraftan araştırmacılar da bu atık malzemelerin yapı malzemesi olarak kullanılabilirliğini araştırmaktadır. Bu çalışmada, doğrudan trafik etkilerine maruz kalan bitümlü sıcak karışım tabakasında meydana gelen gerilmeleri karşılamak için kenevir liflerinin kullanılabilirliği araştırılmıştır. Bu amaçla, ilk olarak seçilen üstyapı tipine göre karışıma ait agrega tane dağılımı belirlenmiştir. Daha sonra Asfalt Enstitüsü MS-2 Marshall test metodu kullanılarak deney numuneleri üretilmiş (15 adet) ve karışımın optimum bitüm içeriğini belirlemek için deneyler yapılmıştır. Çalışmanın ikinci aşamasında ise, doğal lif olan kenevir, karışıma altı farklı oranlarda dâhil edilmiştir (\%0.05, $\% 0.075, \% 0.1, \% 0.125, \% 0.25$ ). Hazırlanan tüm numunelerin fiziksel ve bazı mekanik özellikleri belirlenmiş ve grafiklerle değerlendirilmiştir. Sonuçlar, kenevir liflerinin, bitümlü sıcak karışımların mekanik özelliklerini geliştirdiğini göstermiştir. \% 0.10 kenevir lifi kullanımının, bitümlü sıcak karışımların Marshall Stabilitesini \% 40.183 oranında artırdığı tespit edilmiştir.
\end{abstract}

Anahtar Kelimeler: Kenevir lifi, Asfalt beton, Bitümlü sıcak karışım (BSK), Marshall Stabilite..

\section{Effect of Using Natural Hemp Fiber on Asphalt Concrete Mixtures}

\begin{abstract}
Nowadays, fibrous parts of various plants are left to the nature as waste material. On the other hand researchers are investigating the usability of these waste materials as construction materials. In this study the usability of hemp fibers in order to bear the stresses occurring at hot mixtures asphalts layer, which are directly subjected to the traffic effects was investigated. For this aim, firstly the gradation of the aggregate belonging to the mixture according to the selected pavement type was determined. After than, test specimens were produced by Asphalt Institue MS-2 Marshall test method (15 specimens) and tested for determined the optimum bitumen content of mixtures. In the second phase of the study natural hemp fibers were included in the mixture with the six different contents $(\% 0.05, \% 0.075, \% 0.1, \% 0.125, \% 0.25)$. Physical and some mechanical properties of all prepared samples were determined and evaluated with graphs. The results showed that the hemp fibers improved the mechanical properties of the hot mixture asphalt. It was found that $0.10 \%$ hemp fiber usage increased the Marshall Stability of hot mixture asphalt by $40.183 \%$
\end{abstract}

Keywords: Hemp fiber, Asphalt concrete, Hot mix asphalt (HMA), Marshall Stability. 


\section{GiRiș}

Y ol üstyapısı doğal ve trafik yüklerine maruz kalmaktadır. Taşıtların hareket etmesi sebebi ile dingil yükleri üst yapıya etki etmekte ve bunlardan dolayı düşey basınç gerilmeleri oluşmaktadır [1]. Yol yapımında genellikle sıcak karışım asfalt betonu (BSK) kullanılmaktadır. Asfalt betonu sürüş konforu, stabilite, dayanıklılık ve suya karşı direncin yüksek olmasından dolayı tercih edilmektedir [2].

Asfalt betonu, bitüm ve agrega karışımından meydana gelir ve inşaat mühendisliğinde kullanılan diğer malzemelere göre hassas bir malzemedir. Üstyapıların altındaki nem, toprağı yumuşatır ve üstyapının yapısal kapasitesini yok etmek için temel malzemeleri zayıflatır [3-7]. Öte yandan, trafik yükü, yorulma çatlakları ve üstyapı hataları gibi zararlara neden olmaktadır [7-9]. Trafik yüklerinin artmasıyla birlikte deformasyonlarda da artış beklemek mümkündür. Araştırma konuları yol performansını artırmayı, yol ömrünü proje ömrüne yakın seviyeye getirmeyi ve maliyeti düşürmeyi hedeflemektedir. Bu nedenle, bilim adamları ve mühendisler sürekli olarak karışımlara çeşitli katkı malzemeleri ilave ederek asfalt karışımlarının ve üstyapıları performansını artırmaya yönelik çalışmalar yapmaktadır [10].

Malzemelerin ekonomik boyutu, enerji ve kaynakların verimli kullanımı gibi konular da üstyapı mühendislerini alternatif malzeme ve yol yapım yöntemlerine yöneltmektedir [2]. Son otuz, kırk yılda atık maddelerin yapı üretim malzemesi olarak kullanılabilirliği ve yeniden kazanımı konusunda araştırmalar yapılmaktadır [11].

Çeşitli atıklar bir ham madde gibi kullanılarak yeni bir maddeye dönüştürülmektedir. Bu işleme "geri dönüşüm" adı verilmektedir. Kaynak israfını önlemenin yanında, hayat standartlarını yükseltme çabaları ve ortaya çıkan enerji krizi vb. gerçekleri gören gelişmiş ülkeler atıkların geri kazanılması ve tekrar kullanılması için yöntemler aramış ve geliştirmişlerdir [12].

Günümüzde çeşitli bitkilerin, ağaçların, meyvelerin tüketilen kısımları alınıp, lifli kısımları atıl malzeme olarak doğaya bırakılmaktadır. Bu atıl malzemeler kullanılabilecek iken çöpe atılmakta, bunların yerine farklı kaynaklar kullanılıp, maliyet artmakta ve doğal kaynaklar azalmaktadır [13].

Asfalt karışımlarda ve üstyapılarda kullanılan lifler temel olarak modifiye asfaltın viskoelastisitesini değiştirmek, dinamik modülü, nem duyarlılığı, sürünme direncini, tekerlek izi direncini ve donmaçözülme direncini arttırmak için kullanılan katkı malzemeleridir [3, 14-20]. Bu konularda farklı lif katkılar üzerinde birçok deneysel çalışma yapılmış ve liflerin asfalt karışımlara güçlendirici etkisi olduğunu kanıtlanmıştır.

Yapılan bu çalışmada ise bitümlü sıcak karışımlarda yüksek trafik etkisine doğrudan maruz kalan asfalt kaplama tabakalarında performansın artırılması ve gerilmelerin karşılamasını sağlamaya yardımcı olması amacı ile doğal kenevir liflerinin kullanılabilirliği araştırılmıştır. Bu kapsamda çalışmada kullanılacak agrega ve bitüm seçilmiş ve üzerinde gerekli malzeme deneyleri yapılmıştır. Ampirik hesaplama yöntemleri kullanılarak ön optimum bitüm değerleri tayin edilmiş; yapılan ilk laboratuvar deneyleri sonunda çalışmada kullanılan agrega ve bitüm karışımı (15 farklı numune ile) için optimum bitüm yüzdesi belirlenmiştir. Tespit edilen bu optimum bitüm içeriği ile ağırlıkça farklı doğal kenevir lifi farklı oranlarda $(\% 0, \% 0.05, \% 0.075, \% 0.1, \% 0.125, \% 0.25)$ kullanılarak ve her lif oranı için üçer adet olacak şekilde toplamda 18 numune hazırlanmıştır. Hazırlanan bu numuneler 
Marshall Stabilite deneyine tabi tutulmuş ve kenevir lifinin asfalt beton karışımların performansı üzerine etkisi incelenmiştir.

\section{MATERYAL}

\section{A. ESNEK ÜSTYAPILAR}

Esnek üstyapılar bitümlü kaplama tabakalarından meydana gelir. Tesviye yüzeyiyle sıkı bir temas sağlayan ve trafik yüklerini; kaplama, temel ve alt temel tabakaları yoluyla taban zeminine dağıtan üstyapı şeklidir. Esnek üstyapıların stabilitesi; adezyon, tane sürtünmesi ve kohezyon gibi kullanılan agrega ve bitümün özelliklerinden etkilenir [21]. Bu bölümde çalışmada kullanılmış olan agrega, bitüm ve kenevir lifi hakkında bilgiler verilmektedir.

\section{B. AGREGALAR VE ÖZELLIKLERI}

Asfalt karışımlar içinde barındırdığg agregaların tane dağılımı, maksimum dane boyutu ve dane şekli gibi özellikleri sayesinde stabilite kazanırken, porozite ve dane yüzey dokusu özellikleri sayesinde kazanacağı adezyon ile karışımın stabilitesi artmaktadır. Ayrıca asfalt tabakalarının daha çok gerilme alması ve trafiğin aşındırıcı etkisine maruz kalması gibi nedenlerden ötürü temel tabakasında kullanılan agregalara göre daha üstün niteliklere sahip olması istenir [22]. Karışımın \% 30’u kaba, \% 27'si orta ve \% 42'si ise ince agrega olup \% 1 filler oranı kullanılmıştır. Çalışma kapsamında kullanılan agregalar Düzce ilinde çıkarılan kırma taş agregalar olup; karışım tane dağılımı ve agregaya ait fiziksel özellikleri gösterir tablolar aşağıda verilmektedir (Tablo 1-2).

Tablo 1. Agregaya ait temel fiziksel özellikler.

\begin{tabular}{|c|c|c|c|c|}
\hline Deney Adı & Deney Metodu & Birim & Deney Sonucu & Şartname limitleri \\
\hline $\begin{array}{l}\text { Parçalanma } \\
\text { (los Angeles Aşınma } \\
\text { Kayb1) } 500 \text { devir }\end{array}$ & TS EN 1097-2 & $\%$ & 25 & Max. 30 \\
\hline $\begin{array}{l}\text { Yassılik İndeksi } \\
\text { (5-12 mm Agrega için) }\end{array}$ & TS EN 933-3 & $\%$ & 11 & Max. 25 \\
\hline $\begin{array}{l}\text { Yassilik } \\
\text { (12-19 } \mathrm{mm} \text { Agrega için) }\end{array}$ & TS EN 933-3 & $\%$ & 10 & Max. 25 \\
\hline $\begin{array}{l}\text { Soyulma Mukavemeti \% } \\
\text { Bitümle } \\
\text { yüzey }\left(24 \text { saplanmıs } \quad 60^{\circ} \mathrm{C}\right. \\
\text { suda bekletmeden sonra })\end{array}$ & TS EN 12697-11 & $\%$ & $60-70$ & Min. 60 \\
\hline $\begin{array}{l}\text { Kaba Agregalarda Tane } \\
\text { yoğunluğu (Hacim özgül } \\
\text { ağırlığ1- kuru) }\end{array}$ & TS EN 1097-6 & $\mathrm{gr} / \mathrm{cm}^{3}$ & 2.667 & $\ldots \ldots$ \\
\hline $\begin{array}{l}\text { Kaba Agregalarda } \mathrm{Su} \\
\text { emme (Absorbiyon) }\end{array}$ & TS EN 1097-6 & $\%$ & 0.33 & Max. 2.5 \\
\hline
\end{tabular}


Tablo 2. Agregaya ait tane boyutu dă̆glımı

\begin{tabular}{|c|c|c|c|c|c|}
\hline Elek No. (İnç) & Elek No $(\mathrm{mm})$ & $\begin{array}{c}\text { 12-19 } \mathrm{mm} \\
(3 / 4 "-1 / 2 ") \\
\% \text { Geçen } \\
(\% \text { 30) }\end{array}$ & $\begin{array}{c}5-12 \mathrm{~mm} \\
(1 / 2 "-N o: 4) \\
\% \text { Geçen } \\
(\% 27)\end{array}$ & $\begin{array}{c}\text { 0-5 mm } \\
\text { (No:4-0) } \\
\% \text { Geçen } \\
(\% \text { 42) }\end{array}$ & $\begin{array}{c}\text { \% Elekten } \\
\text { Geçen Sınır } \\
\text { Değerler }\end{array}$ \\
\hline $1 "$ & 25 & 100 & 100 & 100 & 100 \\
\hline $3 / 4 "$ & 19 & 100 & 100 & 100 & $80-100$ \\
\hline $1 / 2 "$ & 12.5 & 93 & 100 & 100 & $58-80$ \\
\hline $3 / 8$ & 9.5 & 8.3 & 99.7 & 100 & $48-70$ \\
\hline No 4 & 4.75 & 0.6 & 84.4 & 100 & $30-52$ \\
\hline No 10 & 2.0 & 0.5 & 6.1 & 98.9 & $20-40$ \\
\hline No 40 & 0.425 & 0.5 & 1.7 & 65.3 & $8-22$ \\
\hline No 80 & 0.180 & 0.5 & 1.6 & 26.8 & $5-14$ \\
\hline No 200 & 0.075 & 0.4 & 1.6 & 17 & $2-7$ \\
\hline
\end{tabular}

\section{BITÜM VE ÖZELLIKKLERI}

Bitümler, doğal kökenli hidrokarbonların bir karışımı veya projenik kökenli (doğal, 1s1 etkisiyle oluşan ergime sonucu meydana gelen) hidrokarbonların bir karışımı ya da bunların her ikisinin kombinasyonudur [23]. Çalışmada TÜPRAŞ rafinerisinden temin edilen B50-70 bitüm kullanılmıştır. Kullanılan bitüme ait kimyasal bileşenler ve temel fiziksel özellikler Tablo 3 ve Tablo 4'de verilmektedir.

Tablo 3. Bitümün kimyasal bileşenleri

\begin{tabular}{lc}
\hline Element & Kütle Yoğunluk \% \\
\hline Karbon & $82-88$ \\
\hline Hidrojen & $8-11$ \\
\hline Nitrojen & $0-1$ \\
\hline Sülfür & $1-6$ \\
\hline Oksijen & $0-1.5$ \\
\hline
\end{tabular}

Tablo 4. Bitüm fiziksel özellikleri

\begin{tabular}{lllll}
\hline Deney Adı & Birim & Deney Metodu & Deney Sonucu & Şartname B50/70 \\
\hline Penetrasyon $25^{\circ} \mathrm{C}, 100 \mathrm{~g}, 5 \mathrm{~s}$ (otomatik) & $0.1 \mathrm{~mm}$ & TS EN 1426* & 59 & $50-70$ \\
\hline Bitüm Özgül Ağırlığı d25/25 & - & TS EN 15326* & 1.024 & $\ldots$ \\
\hline
\end{tabular}

\section{KENEVIR LIFI VE ÖZELLIKLERI}

Anavatanı Asya olan kenevir, 1sirgangillere yakın, cannabinaceae familyasına mensup, tek y1llık odunsu bir bitkidir. Bugün tüm dünyaya yayılmış, cannabis sativa ve cannabis indica olarak iki alt türü bulunmaktadır. Cannabis sativa türü lif üretimi için kullanılan endüstriyel öneme sahiptir. Diğer türünün narkotik özelliği nedeniyle üretimi yasaklanmıştır [24].

Yapılan literatür araştırmaları sonunda en yaygın kullanılan lif boyu çalışmada kullanılmak üzere tercih edilmiş olup; $12 \mathrm{~mm}$ uzunluğundaki kenevir lifleri kırpılmak suretiyle temin edilmiştir. Çalışmada kullanılan kenevir lifinin fiziksel özellikleri Tablo 5'de verilmektedir. 
Tablo 5. Kenevir lifinin fiziksel özellikleri [25]

\begin{tabular}{ll}
\hline Teknik Lif Uzunluğu $(\mathrm{cm})$ & $100-300$ \\
\hline İşlem Görmüş Lif Uzunluğu $(\mathrm{cm})$ & $65-75$ \\
\hline Kuru Özgül Mukavemet $(\mathrm{cN} /$ dtex $)$ & $35-50$ \\
\hline Yaş Özgül Mukavemet $(\%$ Kuru $)$ & 105 \\
\hline E-Modül $(\mathrm{MPa})$ & 12.7 \\
\hline Yıllık Lif Verimi $(\mathrm{Kg} /$ Hektar $)$ & 3000 \\
\hline
\end{tabular}

Cannabis sativa türü kenevirin erkek eşeyli bireylerinden kenevir lifleri elde edilmektedir. Bitkinin boğumlu uzun bir sak1 mevcuttur. Sak kesitinde farklı kategorilerde lifler bulunur. Kullanımda uygun olan lifler primer liflerdir [25]. Şekil 1'de kenevir sakının enine görüntüsü görülmektedir. Görüntüde A kesiti primer lifleri B kesiti ise sekonder lifleri temsil etmektedir. Ayrıca çalışmada kullanılmak üzere kırpılarak hazırlanmış doğal kenevir lifine ait resim Şekil 2'de verilmektedir.

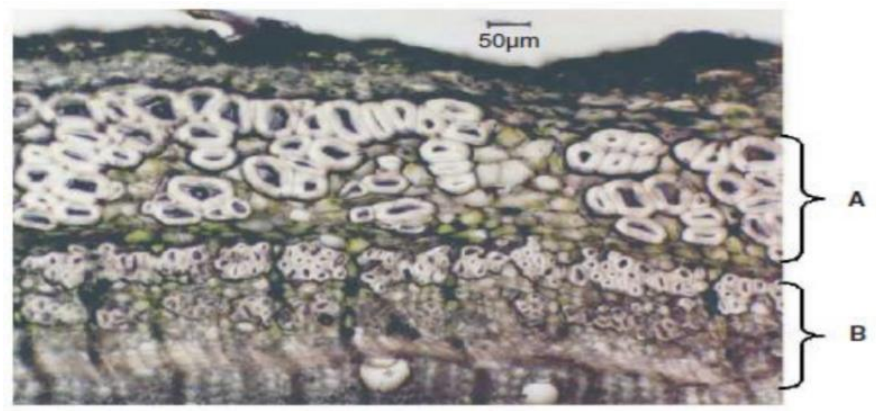

Şekil 1. Kenevir sakının enine kesit görüntüsü; A: Primer lifler, B: sekonder lifler [25]

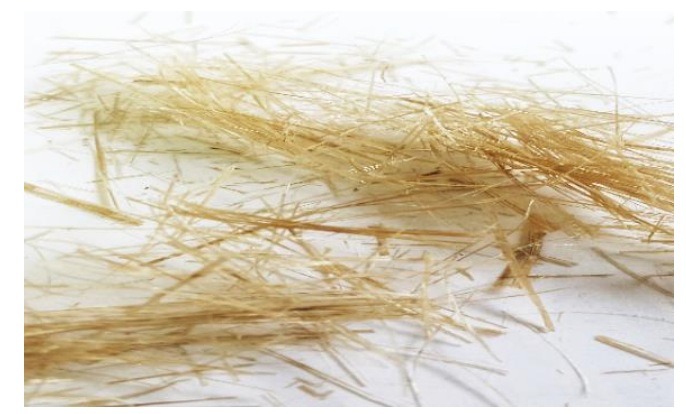

Şekil 2. Asfalt beton karışımlarda kullanılan doğal kenevir lifi

\section{METOT}

Çalışma kapsamında öncelikle hazırlanacak karışımda kullanılacak malzemelere ait fiziksel deneyler yapılmıştır. İkinci aşamada ise teorik hesaplar sonucu elde edilen ön optimum bitüm içeriği kullanılarak beş farklı bitüm yüzdesi $(\% 3.5, \% 4, \% 4.5, \% 5, \% 5.5)$ ile deney numuneleri hazırlanmış (15 adet Marshall numunesi) Marshall test sonuçları ile çizilen grafikler yardımı ile ve optimum bitüm içeriği Denklem 1 [23] yardımı ile \% 4.2 tespit edilmiştir. Optimum bitüm içeriği (Opt. a/c) deneyler sonucu belirlenen maksimum pratik yoğunluğa denk gelen bitüm içeriği, en yüksek Marshall Stabilitesini (MS) veren bitüm içeriği, ortalama boşluk hacmine ait bitüm içeriği ile ortalama bitümle 
kaplı boşluk hacmine denk gelen bitüm içeriklerinin ortalaması ile tespit edilmiştir.

Opt $\frac{a}{c}=\frac{\operatorname{Max} D_{p}\left(\frac{a}{c}\right)+\operatorname{Max} M S\left(\frac{a}{c}\right)+\text { Ort. }_{h}\left(\frac{a}{c}\right)+\text { Ort. } V_{f}\left(\frac{a}{c}\right)}{4}$

Belirlenen optimum bitüm içeriği kullanılarak altı farklı oranda $(\% 0, \% 0.05, \% 0.075, \% 0.10, \% 0.125$, $\% 0.25)$ lif ilave edilerek her bir gruptan üçer adet olacak şekilde toplam 18 Marshall numunesi daha üretilmiş ve numunelere ait fiziksel özellikler tayin edildikten sonra Marshall Stabilite testine tabi tutulmuştur. Böylece tüm karışımlar sonunda en iyi performansa sahip olan en uygun lif oranı belirlenmiştir. Aşağıda çalışmalar boyunca devam ettirilen akış diyagramı Şekil 3'de verilmektedir.

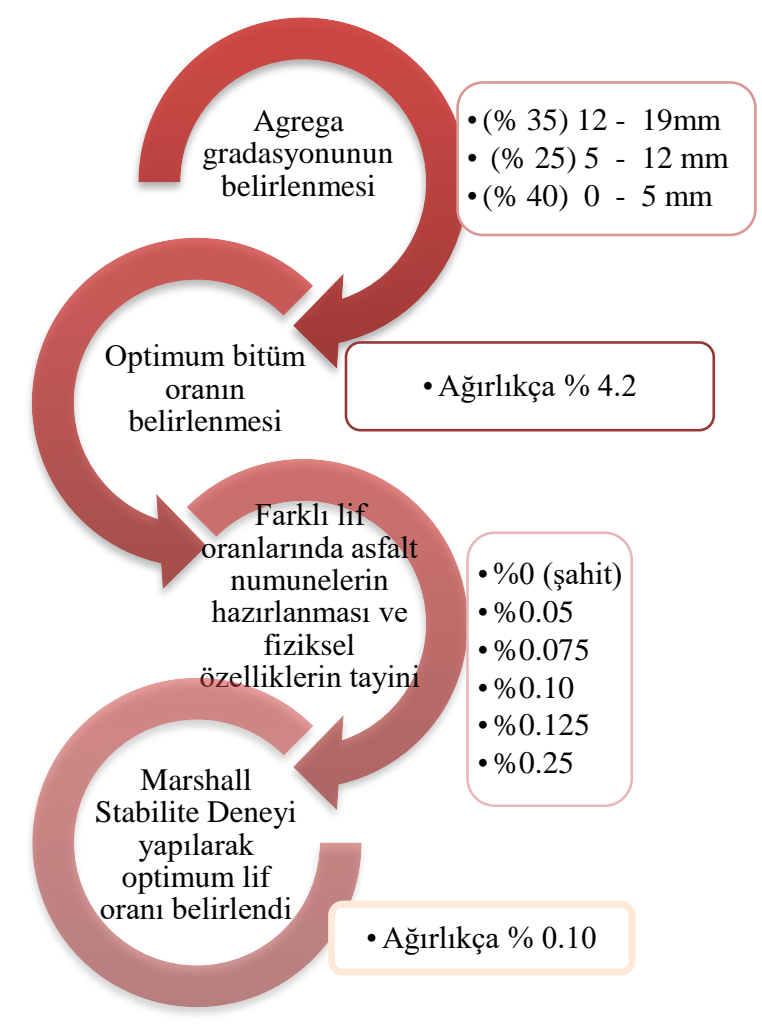

Şekil 3. Yapılan çalı̧̧maya ait akış diyagramı

\section{$\underline{\text { IV. BULGULAR }}$}

Bu bölümde çalışmanın ikinci aşamasında hazırlanan ve en uygun lif oranının belirlenmesinde kullanılan doğal kenevir lifi katkılı karışımlara ait deney sonuçları sunulmuştur. Bu bağlamda bitümlü sıcak asfalt karışımların performansını değerlendirmede kullanılan Akma değeri, numunenin içindeki hava boşluğu oranı (Vh \%), mineral agrega içerisindeki boşluk (VMA \%), bitümle dolu boşluk (Vf $\%$ ), pratik ve teorik birim ağırlık (Dp, Dt) ve Marshall Stabilite (MS) deney sonuçlarına ait grafikler çizilmiş ve detaylı bir şekilde değerlendirilmiştir.

Numunelere uygulanan Marshall Sabilite deneyinde, yükleme sırasında stabilite yükselerek maksimuma ulaşır ve bir noktadan sonra düşmeye başlar. "Marshall Stabilitesi" adı verilen bu değer numunenin kırılmasını sağlayan $\mathrm{kg}$ cinsinden toplam yük miktarıdır. Ayrıca numunenin kırılma sırasında hareket miktarı ölçülerek "Akma” değeri belirlenmektedir [1]. 


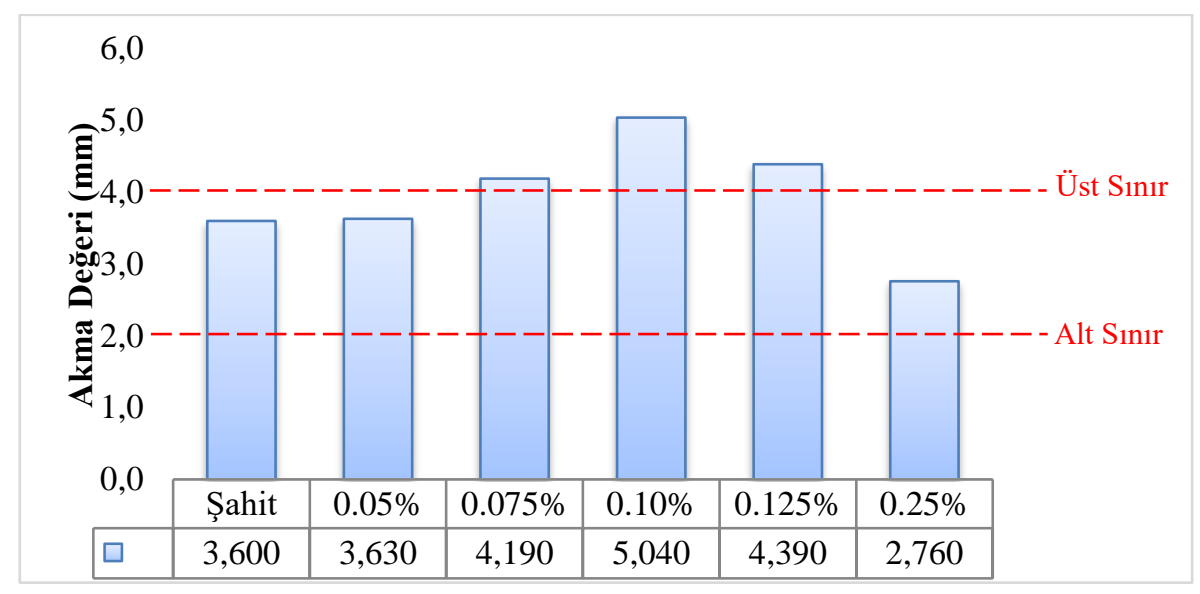

Şekil 4. Farklı lif içeriğine sahip numunelere ait Akma (mm) değerleri

Karayolları Teknik Şartnamesi Standartlarına göre binder tabakasında akma değerleri için en uygun aralık 2-4 mm olarak ifade edilmektedir. Hazırlanan karışımlara ait akma grafiği Şekil 4'de görülmektedir. Akma değerlerinin 2,7 mm $5 \mathrm{~mm}$ arasında olduğu tespit edilmiştir. Lif oranı arttıkça akma değerlerinde belli bir noktaya kadar artış, bir noktadan sonra ise düşüş görülmektedir. Yüksek akma değerleri, plastik davranışa ve kalıcı deformasyon potansiyeline sahip bir asfalt karışımını ifade edecektir. Düşük akma değeri ise karışımda yeterli bitüm oranını, aşırı rijitlik ve düşük sıcaklık yorulma çatlaklarının oluşumuna neden olacaktır [26]. Numunelerdeki akma değerindeki düşüşün sebebi kenevir lifinin yapısal özellikleri sebebiyle karışımda kullanılan bitümün bir kısmını absorbe etmesi, asfalt numunesinin homojen yapısını bozması ve lifin artan hacmi ile aderansı zayıflatması olarak ifade edilebilir.

Hazırlanan numune gruplarına ait teorik (Dt) ve pratik yoğunluk (Dp) değerlerinin ortalaması Şekil 5'de gösterilmiştir. Dt değerleri hacim esaslı hesaplar neticesinde karışıma dahil edilen tüm farklı malzemelerin birim hacim ağırlıkları göz önünde bulundurularak yapılan hesaplamalardır. Dp ise karışımların hazırlanması sonucunda üretilen her numuneye ait deneysel birim hacim ağırlıkları temsil etmektedir. 


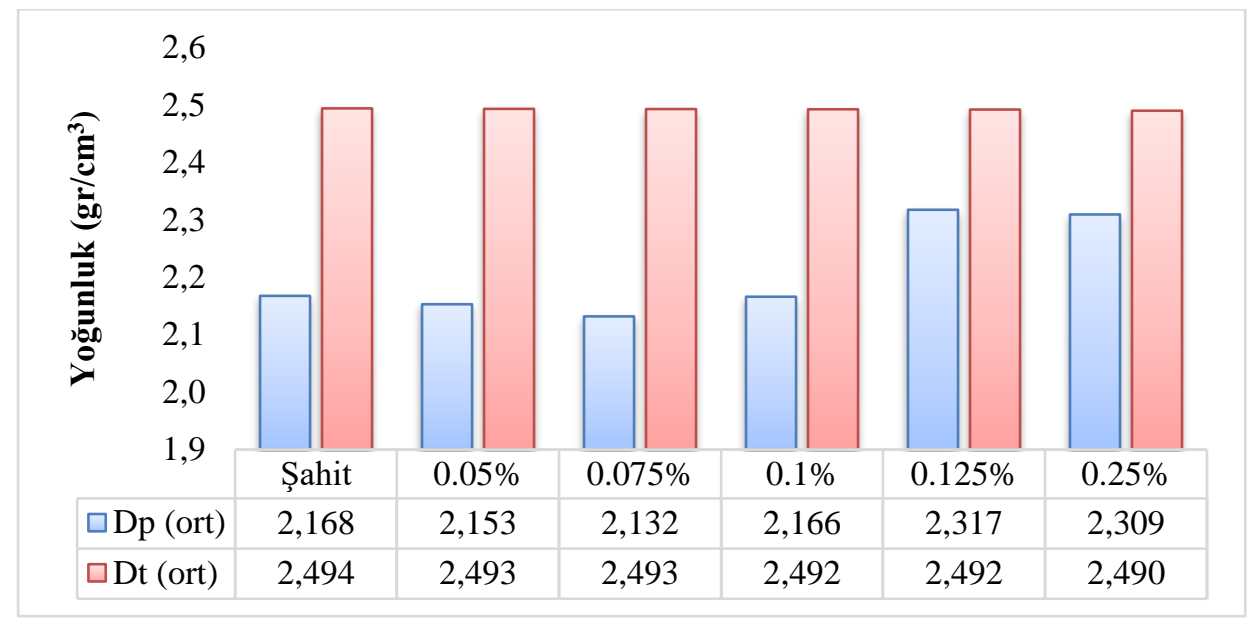

Şekil 5. Farklı lif içeriğine sahip numunelere ait pratik yoğunluk ve teorik yoğunluk değerleri

Deney sonuçları incelendiğinde Dp değerlerinin belli bir noktaya kadar azalma eğilimi gösterdiği bu noktadan sonra ise artmaya başladığı görülmektedir. Artan lif içeriği ile numunenin sıkışma değerinde meydana gelen azalma ve boşluk hacmindeki artış birim hacim ağırlıkların azalmasına sebep olmuştur. Hesapla belirlenen Dt değerinde ise değerler lif katkısının artması ile beraber azalmıştır. En yüksek teorik yoğunluk değeri \%0 lif içerikli numunelerde elde edilirken en düşük değere ise $\% 0.25$ lif ilave edildiğinde ulaşılmıştır.

Vh numuneler içerisindeki hava boşluğunu ifade etmektedir. Numunelere ait hava boşluğu oranı değerleri Şekil 6 'da verilmektedir. Bitümlü sıcak asfalt karışımlarda belli oranda boşluk olması Karayolları Teknik Şartnamesine göre özellikle aranan bir ölçüttür. Ancak bu oran belli bir değeri aşarsa karışımın performansına olumsuz yönde etki etmektedir.

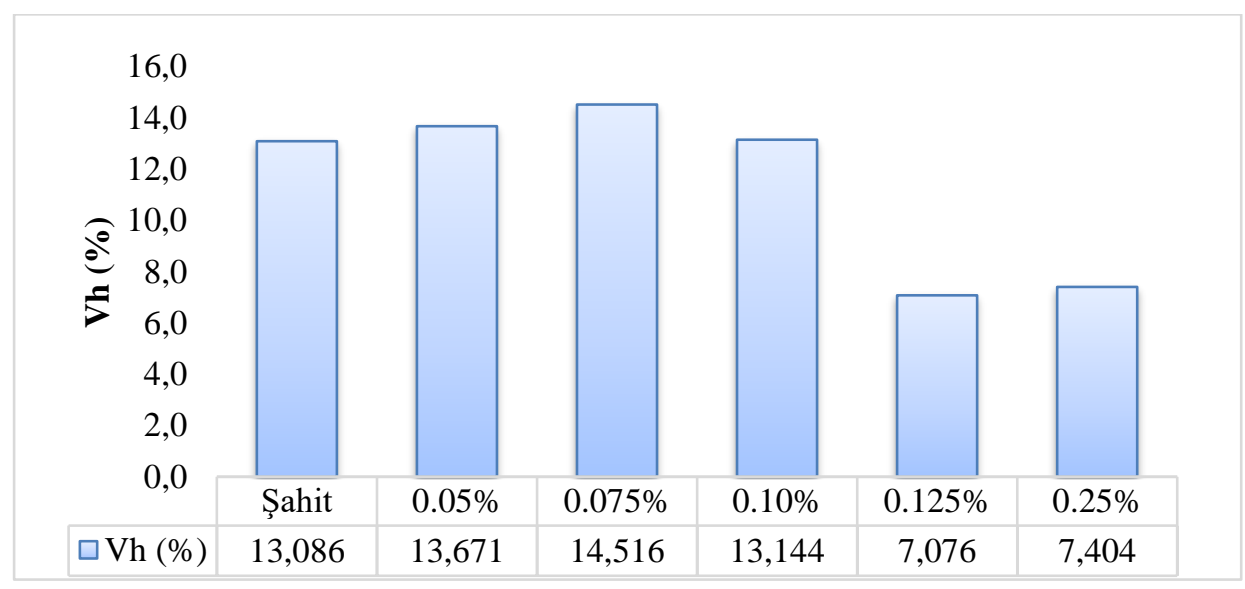

Şekil 6. Farklı lif içeriğine sahip numunelere ait Vh (\%) değerleri

Çalışma sonucunda şahit numuneye göre kıyaslandığında boşluk hacminde numuneler bazında önce artış olduğu sonrasında şahit numunenin de altına düştüğü görülmektedir. En düşük hava boşluğunun $\% 7$ en yüksek hava boşluğunun ise \%14.5 civarında olduğu görülmektedir. 
Vf asfaltla dolu boşluğu ifade etmektedir. Numunelere ait asfaltla dolu boşluk oranları Şekil 7'de sunulmuştur. Boşlukların asfaltla dolu olması homojenliği arttırmakta ve dayanıma olumlu yönde etkimektedir.

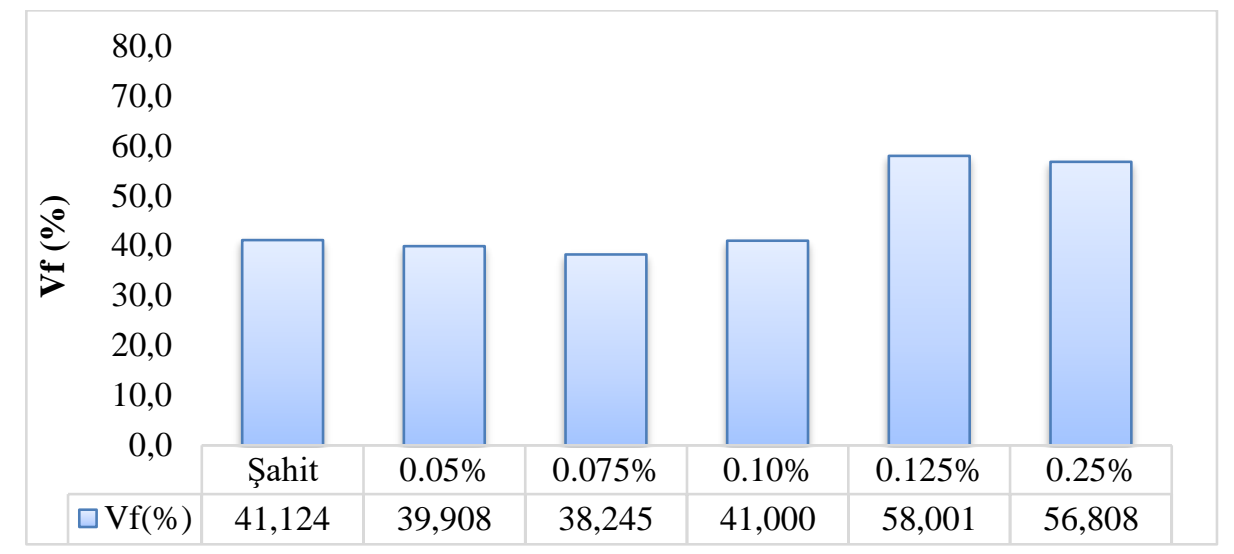

Şekil 7. Farkll lif içeriğine sahip numunelere ait $V f(\%)$ değerleri

Çalışma sonucunda en yüksek Vf değerlerine \%0.25 lif oranında en düşük Vf değerine ise $\% 0.075$ lif içeriğinde hazırlanan numunelerde ulaşılmıştır. En yüksek Vf \%56.8 olurken en düşük Vf değerinin \%38.2 olduğu tespit dilmiştir.

Mineral agregalar arası boşluk (VMA) efektif bitüm miktarını ve hava boşluğunu içeren, sıkıştırılmış kaplama karışımının agrega daneleri arasındaki boşluk olarak tanımlanır ve toplam hacmin yüzdesi olarak hesaplanır. Tablo içerisindeki ondalık ayıracında virgül yerine nokta kullanılmalı.

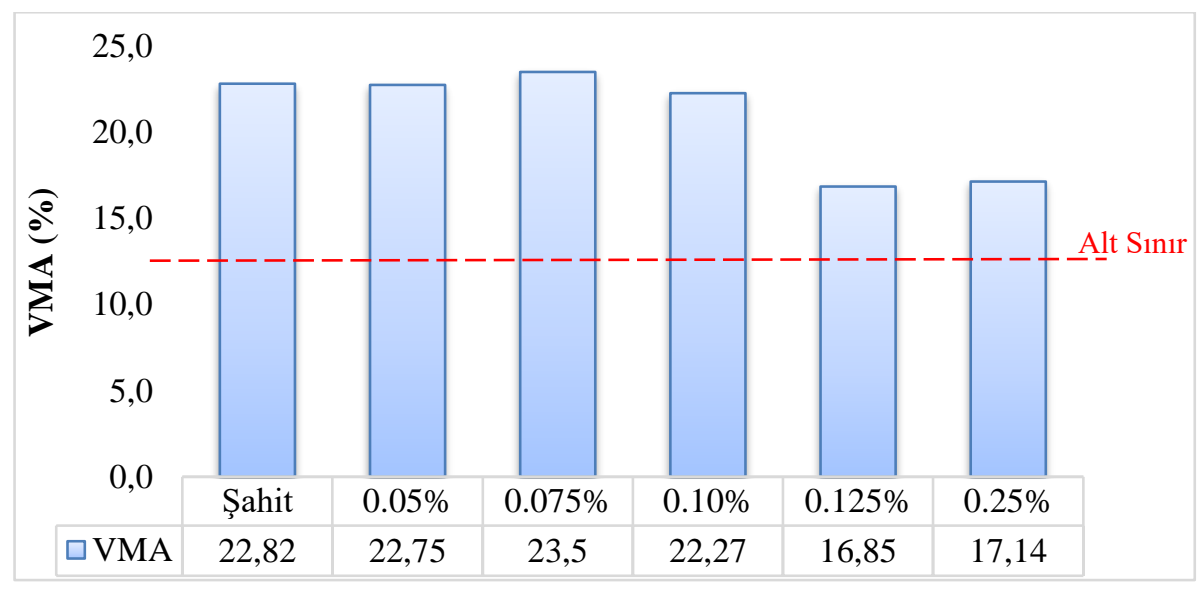

Şekil 8. Farklı lif içeriğine sahip numunelere ait VMA değerleri

VMA değerleri Şekil 8'de sunulmuştur. Grafik incelendiğinde VMA değerinin belli bir lif oranından sonra azalmaya başladığı görülmektedir. Lifler boşlukları kapladığı için lif oranı arttıkça azalma durumu söz konusu olmuştur. Karayolları Teknik Şartnamesine göre sıcak karışımlarda bulunması gerekli minimum VMA değerinin $16 \%$ olduğu ifade edilmektedir. Çalışmada kullanılan tüm lif içeriklerin bu sınır değerin üzerinde bir VMA değerine ulaşılmıştır.

Şartnameye göre bitümlü karışımlarda kaplama tabakası binder ve aşınma olarak iki grupta ele alınır. Bunlar üstyapıda tabakalı sistemi meydana getirirler, aynı zamanda farklı kriterler göz önünde 
bulundurularak hazırlanırlar. Çalıma kapsamında binder kaplama tabakası için tasarımlar yapılmış ve sonuçlar da buna göre değerlendirilmiştir. Numunelere uygulanan Marshall Deneyi sonucunda elde edilen Stabilite değerleri Şekil 9'da verilmektedir.

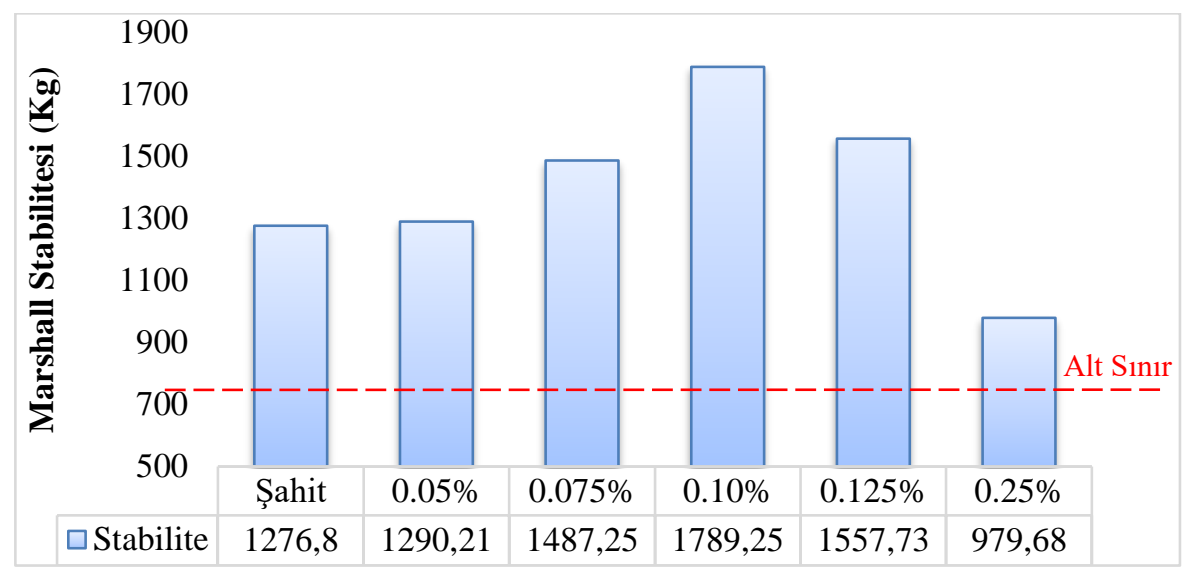

Şekil 9. Farklı lif içeriğine sahip numunelere ait Marshall Stabilite değerleri

Karayolları Teknik Şartnamesinin belirlemiş olduğu koşullar doğrultusunda binder tabakası stabilite değeri minimum $750 \mathrm{~kg}$ olmalıdır. Kullanılmış olan asfalt numunelerinden $\% 0$ lif oranına sahip şahit numunenin stabilite değeri $1276.8 \mathrm{~kg}$ ile bu şartı sağlamaktadır. Çalışmada lif oranı arttıkça stabilite değerlerinde artış \%0.10 lif içeriğine kadar devam etmekte bu lif içeriğinden sonraki karışımlarda ise stabilite değerinin düşmeye başladığı görülmektedir. En yüksek stabilite değeri 1790 kg olarak tespit edilmiştir. Bitümlü sıcak asfalt karışımlara ilave olarak ağırlıkça $\% 0.10$ oranında kenevir lifinin eklenmesi Stabilite değerini şahit numunelere göre $\% 40$ civarında arttırdığ 1 tespit edilmiştir. \%0.125 oranında sonra ise eklenen daha fazla lifin karışımın performansına olumsuz yönde etki ettiği görülmektedir. Ancak bu karışımlarda dahi stabilite değerinin şahit numunelerin stabilitesinin altına düşmediği görülmektedir.

\section{$\underline{\text { V. SONUC }}$}

Asphalt Instıtue MS-2 Marshall metoduna göre yapılan deneyde kalıbın içindeki asfalt numunesine 75 darbeyle üst ve alt yüzeylerde sıkıştırma yapılmıştır. $135-140{ }^{\circ} \mathrm{C}$ 'de karışım sıcaklığına sahip numuneler farklı kenevir lifi oranına sahip 3'er adet numune ve kenevir lifinin kullanılabilirliğinin denetlenmesi amacıyla \% 0 lif oranına sahip 3 adet şahit numune hazırlanmıştır. Optimum bitüm tayini için 15, en uygun kenevir lifi içeriğinin tayini içinse 18 olmak üzere toplamda 33 adet numune hazırlanmıştır. Hazırlanan numunelere fiziksel ve mekanik deneyler yapılmıştır. Sonuçlar değerlendirilmiştir.

Çalışmada $12 \mathrm{~mm}$ boyutlarındaki doğal kenevir lifi \%0 (şahit), \%0.05, \%0.075, \%0.10, \%0.125, $\% 0.25$ oranlarında karışıma ilave edilmiştir. Karışımın en önemli performans parametresi olarak ifade edilen Marshall Stabilite değerine bakıldığında \%0 lif oranına sahip (şahit) numunenin stabilite değeri 1276.8 kg olduğu karışıma lif ilave edildikçe bu değerin artış gösterdiği tespit edilmiş; en yüksek stabilite olan $1789 \mathrm{~kg}$ değerine \%0.10 lif ilaveli karışımlarda ulaşılmıştır. Bu değer Karayolları Teknik Şartnamesi binder tabakası minimum stabilite değerinin oldukça üzerindedir. $\% 0.125$ ve $\% 0.25$ kenevir lif katkılı karışımlarda stabilite grafiğine göre düşme eğilimi olsa da şartname sınırının 
üzerinde sonuçlar verdiği görülmektedir. Stabilite değerinin optimum kenevir lifi noktasından sonra düşme eğilimi göstermesi literatürde farklı lif katkılı karışımlar için de karşılaşılan bir durum olmuştur. Karışımda belli bir orandan sonra ilave edilen lif performansa katkı sağlamanın dışında bir noktadan sonra olumsuz etki ortaya koyacaktır. Ayrıca unutulmaması gereken bir diğer nokta da karışımda en iyi performansı veren optimum lif değerinin tespit edilmesi ekonomik kaygıların da ortadan kalkmasına yardımcı olacaktır.

Genel olarak yapılan deneylerden elde edilen sonuçlar ele alındığında, akma değerinde ve boşluk hacminde belli oranlarda artışa sebep olsa da kenevir lifinin sıcak asfalt karışımlarında kullanılması üstyapının performansına olumlu katkı sağlamaktadır. Kenevir lifi katkılı bitümlü sıcak karışımların ağır taşı trafiği ve yüksek trafik hacmi olan yerlerde kullanılabilecek nitelikte olduğu düşünülmektedir.

Ayrıca çalışmalar sonucunda karışıma ilave edilen lifin aşırı artması ile homojen karışımın gerçekleştirilememesi, buna bağlı olarak sıkıştırmanın etkilenmesi ve nihayetinde boşluk hacminde artışlar gözlenmiştir. Artan boşluk hacminin ise Marshall Stabilite değerine olumsuz etki yaptığı görülmektedir. Diğer taraftan karışıma ilave edilen lifin karışım içerisindeki bitümü emmesi sonucu karışımın bitüm içeriğini de etkilediği söylenebilir. Aşırı artan lif içeriği agrega karışımı için tespit edilen optimum bitüm içeriğini bozmakta ve işlenebilirliği de olumsuz yönde etkilemektedir. $\mathrm{Bu}$ nedenle lifli asfalt karışımlarda bu hususa özellikle dikkat edilmelidir.

Çalışmada kullanılan doğal kenevir lifinin stabilitenin yanında, diğer mekanik özelliklere de katkı sağlayacağı kuşkusuzdur. Kenevir lifli karışımların dinamik modülü, neme ve donma-çözülmeye hassasiyeti, karışımların tekerlek izi oluşumlarına karşı tepkisi üzerine ayrıca detaylı çalışmalar sürdürülebilir.

\section{KAYNAKLAR}

[1] F. Umar, E. Ağar, Yol Üst Yapısl, 3. bask1, İstanbul, Türkiye: İTÜ İnşaat Fakültesi Matbaası, 1991, ss. 339.

[2] M. Y1lmaz, "Effects of Using Asphaltite as Filler on Mechanical Properties of Hot Mix Asphalt," Construction and Building Materials, vol. 25, no. 11, pp. 4279-4286, November 2011.

[3] S.M. Abtahi, M. Sheikhzadeh, S.M. Hejazi, "Fiber-reinforced asphalt-concrete - A review," Construction and Building Materials, vol. 24, pp. 871-877, 2010.

[4] Marienfeld and K. Guram, "Overview of field installation procedures for paving fabrics in North America," Geotext Geomem, vol. 17, no. 2, pp.105-20, 1999.

[5] M. Castro, A. Sanchez, "Estimation of asphalt concrete fatigue curves - a damage theory approach," Construction and Building Materials, vol. 22, no. 6, pp. 1232-8, 2008.

[6] C. Görkem, B. Şengöz, "Predicting stripping and moisture induced damage of asphalt concrete prepared with polymer modified bitumen and hydrated lime," Construction and Building Materials, vol. 23, no. 6, pp. 2227-36, 2009. 
[7] G. Airey, A. Collop, S. Zoorob, C. Elliott, "The influence of aggregate, filler and bitumen on asphalt mixture moisture damage," Construction and Building Materials, vol. 22, no. 9, pp. 2015-24, 2008.

[8] D.V. Ramsamooj, "An innovative technique for using polymer composites in airport pavement rehabilitation," Composites: Part B, vol. 32, no. 1, pp. 57-66, 2001.

[9] X. Chen and B. Huang, "Evaluation of moisture damage in hot mix asphalt using simple performance and superpave indirect tensile tests," Construction and Building Materials, vol. 22, no. 9, pp. 1950-62, 2008.

[10] R.L. Fitzgerald, "Novel applications of carbon fiber for hot mix asphalt reinforcement and carbon-carbon pre-forms," M.S. thesis, Dept. of Chemical Engineering, Michigan Technological University, 2000.

[11] M. Karacasu, Ş. Bilgiç, “Atık Lastik Katkısının Sıcak Asfalt Özelliklerine Etkisi,” Eskişehir: Eskişehir Osmangazi Üniversitesi Mühendislik Mimarlık Fakültesi Dergisi, c. XXII, s. 2, 2009.

[12] C. Gürer, H. Akbulut, G. Kürklü "İnşaat Endüstrisinde Geri Dönüşüm ve Bir Hammadde Kaynağı Olarak Yapı Malzemelerinin Yeniden Değerlendirilmesi," Endüstriyel Hammeddeler Sempozyumu, Türkiye, 2004.

[13] Anonim, (25 Aralık 2017). [Online]. Erişim:http://www.bilgiustam.com/geri-donusum-nedirneden-önemlidir/

[14] H. Huang, T.D. White, "Dynamic properties of fiber-modified overlay mixture," Trans Res Rec, vol. 1545, pp. 98-104, 1996.

[15] S. Wu, Q. Ye, N. Li, H. Yue, "Effects of fibers on the dynamic properties of asphalt mixtures," J Wuhan Univ Technol-Mater Sci Ed, vol. 22, pp. 733-6, 2007.

[16] B.J. Putman, S.N. Amirkhanian, "Utilization of waste fibers in stone matrix asphalt mixtures, resources," Conserv Recycle, vol. 42, pp. 265-74, 2004.

[17] Chen $\mathrm{H}, \mathrm{Li} \mathrm{N}, \mathrm{Hu} \mathrm{C}$, Zhang Z. "Mechanical performance of fibers-reinforced asphalt mixture," J Chan Univ (Nat Sci Ed), vol. 24, no. 2, pp. 1-5, 2004.

[18] J. Echols, "New mix method for fiber-reinforced asphalt," Public Works, vol. 119, no. 8, pp. 72-3, 1989.

[19] S. Tapkın, "The effect of polypropylene fibers on asphalt performance," Build Environ, vol. 43, pp. 1065-71, 2008.

[20] D.A. Maurer, G.J. Malasheskie, "Field performance of fabrics and fibers to retard reflective cracking," Geotext Geomem, vol. 8, pp. 239-67, 1989. 
[21] Ü. Giriş, "Esnek üstyapılar ile rijit üstyapilarin teknik ve ekonomik yönden karşılaştırılması", Yüksek Lisans Tezi, İnşaat Mühendisliği, Gazi Üniversitesi, Ankara, Türkiye, 2007.

[22] A. Tunç, Kaplama Mühendisliği ve Uygulamaları, İstanbul, Türkiye: Asil Yayın Dağıtım, 2004.

[23] A. Tunç, Esnek Kaplama Malzemleri El Kitabı, Ankara, Türkiye: Asil Yayın Dağıtım, 2004, ss. 352 .

[24] M. Harmancıoğlu, G.Yazıcı̆ğlu, Bitkisel Lifler, Ege Üniversitesi Tekstil Fakültesi Yayınları no :3, Ege Üniversitesi matbaas1, İzmir, 1979, ss. 336.

[25] G. Gedik, O.O. Avinç, A. Yavaş, "Kenevir lifinin özellikleri ve tekstil endüstrisinde kullanımıyla sağladığı avantajlar," Tekstil Teknolojileri Elektronik Dergisi, c. 4, s. 3, pp. 39-48, 2010.

[26] P. Lavin, Asphalt Pavements: A Practical Guide to Design, Production and Maintenance for Engineers and Architects, Florida, CRC Press, Published February 20, 2003, pp. 462. 